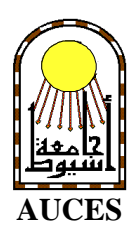

\title{
DETECTION OF ORGANOCHLORINE PESTICIDE RESIDUES IN SAMPLES OF COW MILK COLLECTED FROM SOHAG AND QENA GOVERNORATES
}

\author{
Abdel-Wahab A. Dawood ; Ragaa M. Abd El-Maaboud ; Maha A. Helal*; \\ Sohir A. Mohamed* and Waleed H. Ali* \\ Forensic Medicine and Toxicology Departments, Faculties of Medicine, \\ Assiut and South Valley* Universities
}

\begin{abstract}
:
Organochlorine pesticides have been used extensively especially in tropical countries in malaria control programs as well as control of agricultural pests. However, much of the food we eat contain pesticide residues. Analysis of organochlorine compounds are carried out because of their potential health hazardous effect on humans. In this study, milk was monitored using HPLC, for six organochlorine pesticide residues (DDT, dielderin, endrin, heptachlor, heptachlor epoxide and lindane) to determine the degree of environmental contamination with them. The study included 40 samples of fresh dairy cow milk which were collected from some villages at Qena and Sohag Governorates (20 from Qena and 20 from Sohag) in the period from June 2002 to December 2002. The results of the study revealed that $82.5 \%$ were contaminated with one or more of the investigated organochlorine pesticides. The distribution was : (95\%) of the samples from Qena and (70\%) from Sohag. DDT complex was the most frequent contaminant. It was found in $30 \%$ of milk samples followed by lindane and heptachlor as each of them was found in $22.5 \%$ of milk samples. Endrin was found in $\mathbf{1 7 . 5 \%}$ and then dieldrin and heptachlor epoxide as each was found in $15 \%$ of milk samples. The mean concentration of DDT complex was $0.1003 \mathrm{ppm} \pm 0.19$. The mean concentration of heptachlor was $0.0575 \mathrm{ppm} \pm \mathbf{0 . 0 1 3}$. Heptachlor epoxide was found in a mean concentration of $0.053 \mathrm{ppm} \pm \mathbf{0 . 0 1}$, while the mean concentration of dieldrine was $0.1273 \mathrm{ppm} \pm$ 0.02 .

On comparison of the EDI (Estimated Daily Intake) in this study with the ADI (Average Daily Intake) data recommended by the Food and Agricultural Organization/ World Health Organization (FAO/WHO 1993), It was found that None of these values exceed the recommended values. The results of this work indicated that in spite of the banning much of organochlorine pesticides still contaminating the environment resulting in contamination of food stuffs, particularly milk. There is a potential risk of the consumption of such contaminated milk on human's health particularly infants and children.
\end{abstract}

\section{INTRODUCTION:}

Milk is at risk of being contaminated by a wide variety of chemical residues introduced via treatment of the cow, its feed, the milking environment and the processing plant. The potential chemical contaminants are: Antibiotics, Hormones, Disinfectants, Nitrites, 
Pesticides, Polychlorinated Biphenyls (PCBs), Mycotoxins, Toxic metals and Dioxins (Heeschen and Harding, 1995).

Most insecticides exert their effects by poisoning the insect nervous system. Although obvious differences exist between mammalian and insect nervous systems, it is important to recognize that the mechanisms of toxicity of most insecticides are similar in humans and insects. The only selectivity that exists is a function of dose; when properly applied, the amount of insecticide that is delivered to the target organism is at a lethal concentration, whereas the dose delivered to non-target organisms is hopefully below the threshold of toxicity. Because of this reliance on dose for target organism specificity, the potential for toxic effects in humans must always be considered when insecticide exposures occur (Joy, 1982).

Organochlorine pesticides are substances containing chemically combined chlorine and carbon. They may be grouped into three general classes:the dichlorodiphenylethanes (DDT, DDD, dicofol, etc.), the chlorinated cyclodienes (aldrin, dieldrin, heptachlor, etc.), the hexachlorocyclohexanes (lindane). These compounds differ substantially between and within groups with respect to toxic doses, skin absorption, fat storage, metabolism, and elimination. The signs and symptoms of toxicity in humans, however, are remarkably similar except for DDT (Hayes, 1991).

Organochlorine pesticides persist and tend to bioaccumulate in the environment. These qualities make them the most dangerous group of chemicals to which natural systems can be exposed. Organochlorine pesticides have been used extensively to combat both agricultural and cattle breeding pest infestation. Dairy herds are mainly exposed to these contaminating residues through their food. After the residues have been metabolized, they are stored in fat reserves from which they enter the circulation and partially eliminated in the milk (Martinez et al., 1997). It is well known that, the widespread use of organochlorine compounds have caused serious problems to man due to their bioaccumulation in several organs. The majority of these compounds are toxic in high levels and few are carcinogenic in small animal tests (Fytianos et al., 1985). The occurrence of persistent organochlorine compounds in the environment is changing relatively slowly over a span of years; similar time trends are characteristic of contents in fish, meat, eggs, and diary products, which are the foods with the greatest contributions to the intake of organochlorine compounds (Watterson 1991 and Robertson et al. 2002). The most common effects of the wide spread of organochlorine compounds in the environment are birth defects, neurological effects and behavioral effects, reproductive effects and cancer (Windham, 2002). An epidemiological study in Belgium found that women with at least $0.5 \mathrm{ppb}$ levels of organochlorine pesticides, DDT and/or hexachlorobenzene have at least a 5 times higher incidence of breast cancer than those with lower levels (Tilman, 2003).

\section{Aim of the work:}

This study aimed to monitor six of organochlorine pesticide residues (DDT complex, dielderin, endrin, heptachlor, heptachlor epoxide and lindane) in dairy cow milk collected directly from farms in Sohag and Qena Governorates in a trial to determine the degree of environmental contamination with organochlorine pesticides. Also to compare the results of this study with other national and international studies.

\section{MATERIALS AND METHODS:}

\section{A-Milk samples:}


Forty samples of fresh dairy cow milk were collected directly from farms in some villages of Qena and Sohag Governorates (20 samples from Qena and 20 samples from Sohag) in the period from June 2002 to December 2002.

\section{B-Chemicals and reagents:}

\section{Solvents:}

1-N-hexane: $95 \%$, Laboratory Rasayan.

2-Acetonitrile: (Methyl cyanide), 99.7\% (HPLC grade), BDH laboratory supplies (England).

3-Methanol: $\quad 99.8 \%$ (HPLC grade), BDH laboratory supplies (England).

4-Toluene: $\left(\mathrm{C}_{6} \mathrm{H}_{5} \mathrm{CH}_{3}\right), 92 \%$, Morgan chemicals.

\section{Organochlorine compounds standards:}

Gamma- HCH, DDT, dieldrin, endrin, heptachlor and heptachlor epoxide were obtained from Kapher El-Ziat Company for Chemicals and Pesticides. The standard solutions of organochlorine pesticides were prepared in n-hexane (Clarke, 1986).

\section{C-Apparatus:}

Organochlorine pesticides were detected by high performance liquid chromatography (HPLC) in Faculty of Science, Cairo University which was Shimadzu model (Japan) equipped with LC-9A pump, SPD-M6A detector. Column C18, Helium degassing (DGU-2A) and UV detector were used.

\section{Adsorbent:}

Aluimina, which is neutral, activity grade I, 80/200 mesh. It was activated by heating for 16 hour at 260 degrees celsius, then cooled at room temperature before use. Alumina for column chromatography was obtained from Sigma chemical company, Germany.

The mobile phase was methanol: water $(80: 20)$.
Extraction of organochlorine pesticides in this work was based on solid phase extraction using column for selective sample preparations.

D-Methods: (according to Clarke,1986).

1-Sample preparation: Each sample (1/2 liter of fresh dairy milk) was thoroughly manually mixed and subsamples of $50 \mathrm{ml}$ was mixed with $0.5 \%$ toulene and was shaked by a shaker for 10 minutes.

2-Column conditioning: The column was washed with $10 \mathrm{ml}$ acetonitrile, then washed with $10 \mathrm{ml}$ distilled water.

3-Sample application: The sample was sucked through the column then $10 \mathrm{ml}$ distilled water was added twice then the column was dried for 30 minutes under vacuum.

4-Elution: Organochlorine pesticide was eluted with $2 \mathrm{ml} \mathbf{n}$-hexane. Vacuum was applied at the column end. Sucking the eluent through a column can be obtained by putting the column in a centrifuge tube. The elute was injected by syringe in HPLC apparatus.

5-For calibration of the apparatus standard solution of the organochlorine pesticides were injected through the column.

\section{Calculation of The Results:}

A calibration curve for each organochlorine pesticide was obtained by injecting different concentrations of the pesticide into the HPLC column and measuring the absorption corresponding to each concentration at $240 \mathrm{~nm}$. The calibration curve will be used for quantitative estimation of the organochlorine insecticides according to Beer's law (linear relationship between the concentration and absorption) as shown :

Column type: Chromabond C18/3ml/200mg. 
Beer's law: $A=\varepsilon b c$

Where:

A is the absorption.

$\varepsilon \quad$ is the molar extension coefficient.

b is the light path length $(\mathrm{cm})$.

c is the molar concentration.

The amount of each type of organochlorine pesticide in the injected elute was determined by applying the obtained value of absorption onto the calibration curve of the standard solution of this pesticide and then the concentration corresponding to this absorption is observed. The values obtained from HPLC were expressed in $\mu \mathrm{g} / 50 \mathrm{ml}$. These values were multiplied by 20 to have the result in $\mu \mathrm{g} / \mathrm{L}$ (ppm) and multiplied by 1000 to have the result in ppb.

\section{Daily intake:}

Calculation of daily intake of organochlorine pesticides in milk was based on the recommended daily consumption of milk in Egypt and the detected concentrations of each pesticide in analyzed milk samples assuming that the person weighting $60 \mathrm{~kg}$. consumes 2 glasses of milk/day $(343 \mathrm{ml})$,

Statistical processing of the data included calculation of the minimum, maximum, median and mean levels of organochlorine pesticide residues and the standard deviation of the mean ( \pm SD).

\section{RESULTS:}

Forty samples of cow milk collected from some villages of Qena and Sohag Governorates (20 samples from Qena and 20 samples from Sohag) in the period from June 2002, to December 2002 were investigated for the presence of six organochlorine pesticide residues. The investigated organochlorine compounds were: p,p'-DDT with its metabolites p,p'-DDE and p,p'-DDD(the values for these three substances were reported here as the sum of the three, referred to as DDT complex), dielderin, endrin, heptachlor, heptachlor epoxide, and lindane.

The frequency distribution of organochlorine pesticide residues detected in the analyzed milk samples is shown in table (1). For Qena milk samples 19 out of 20 analyzed samples, $(95 \%)$ were contaminated with one or more of the investigated organochlorine pesticides, while only one sample $(5 \%)$ was free from contamination with any organochlorine pesticide residues. Seven samples $(35 \%)$ were contaminated with DDT complex, three samples (15\%) were contaminated with dieldrin, five samples $(25 \%)$ were contaminated with endrin, six samples $(30 \%)$ were contaminated with heptachlor, four samples $(\mathbf{2 0 \%})$ were contaminated with heptachlor epoxide and four samples $(20 \%)$ were contaminated with lindane.

For Sohag milk samples 14 out of 20 analyzed samples, $(\mathbf{7 0 \%})$ were contaminated with one or more of the investigated organochlorine pesticides, while the other six samples $(30 \%)$ were free from contamination with any organochlorine pesticide residues. Five samples $(25 \%)$ were contaminated with DDT complex, three samples (15\%) were contaminated with dieldrin, two samples $(\mathbf{1 0 \%})$ were contaminated with endrin, three samples (15\%) were contaminated with heptachlor, two samples $(10 \%)$ were contaminated with heptachlor epoxide and five samples $(25 \%)$ were contaminated with lindane.

Table (2) shows the minimum, maximum, and median values of organochlorine pesticide residues in a liter of diary milk collected from Qena and Sohag $(\mu \mathrm{g} / \mathrm{L})(\mathrm{ppm})$.

Table (3) shows the range and the mean values of the organochlorine pesticides detected in a litre of whole milk. The minimal detected 
amount of DDT complex was $0.064 \mathrm{ppm}$ and the maximal detected amount was $0.128 \mathrm{ppm}$, with a mean concentration of $0.1003 \pm 0.019 \mathrm{ppm}$. The level of dieldrin in milk ranged from 0.096 to 0.162 with a mean concentration of $0.1273 \pm$ 0.02 ppm. Endrin levels ranged from 0.036 to $0.082 \mathrm{ppm}$ with a mean concentration of $0.058 \pm$ 0.013 ppm. The level of heptachlor ranged from 0.038 to $0.082 \mathrm{ppm}$ with a mean concentration of $0.0575 \pm 0.013 \mathrm{ppm}$. Heptachlor epoxide levels ranged from 0.044 to $0.072 \mathrm{ppm}$ with a mean concentration of $0.053 \pm 0.01 \mathrm{pp}$ and the level of lindane in milk samples from between 0.15 to $0.196 \mathrm{ppm}$ with a mean concentration of $0.17 \pm$ $0.016 \mathrm{ppm}$. The estimated daily intake of an adult person weighting $60 \mathrm{~kg}$. from each of the investigated organochlorine compounds was demonstrated in the table.

Fig.(1) shows the frequency of whole dairy milk samples contaminated with organochlorine pesticides. Thirty three samples $(82.5 \%)$ were contaminated with one or more of the investigated organochlorine pesticides, while only seven samples $(\mathbf{1 7 . 5 \%})$ were free from contamination with any organochlorine residues.

Fig.(2) shows the number of detected organochlorine pesticide residues in milk samples. Twenty milk samples $(50 \%)$ were contaminated with only one type of organochlorine pesticide. Ten $(25 \%)$ samples were contaminated with two different types of organochlorine pesticides and three samples $\mathbf{7 . 5 \% )}$ were contaminated with three different types of organochlorine pesticides.

Fig. (3) shows the number of positive milk samples contaminated with each organochlorine pesticides. Twelve milk samples $(30 \%)$ were contaminated with DDT complex followed by lindane and heptachlor as each of them has been detected in nine milk samples $(\mathbf{2 2 . 5 \% )}$. Endrin has been detected in seven milk samples (17.5\%). Heptachlor epoxide and dieldrin each has been detected in six milk samples $(15 \%$ of milk samples show heptachlor epoxide and $15 \%$ show dieldrin).

Fig.(4) shows the mean values of organochlorine pesticide residues detected in dairy milk samples collected from Qena and Sohag in (ppb). The mean value of DDT complex in milk sample collected from Qena was 108.5 ppb and from Sohag was 88.8 ppb. The mean value of dieldrin in samples collected from Qena was 153.5ppb and from Sohag was 128 ppb. The mean value of endrin was 53.2 ppb in the samples collected from Qena and $70 \mathrm{ppb}$ in samples collected from Sohag.The mean value of heptachlor was 59.6 in samples collected from Qena and 53.3 ppb in samples collected from Sohag. The mean values for heptachlor epoxid in samples collected from Qena was 55.5 ppb and 49 ppb in samples collected from Sohag. Finally, the mean values of lindan in samples collected from Qena was 171.5 ppb and $168.8 \mathrm{ppb}$ in samples collected from Sohag. 
Ass. Univ. Bull. Environ. Res. Vol. 7 No. 2, October 2004

$-110-$ 
Ass. Univ. Bull. Environ. Res. Vol. 7 No. 2, October 2004

-111- 


\section{DISCUSSION:}

Although many countries have banned or severely restricted the use of most dangerous organochlorines, it is thought that many of these compounds have been or continue to be used in large quantities in some developing tropical countries for agricultural and public health reasons as control of malaria. Presence of organochlorine residues in soils that were heavily treated years ago is suspected to be an important present-day source (Fiedler et al., 2000).

This study included 40 samples of fresh dairy milk collected randomly from several villages at Qena and Sohag governorates (20 samples from Qena and 20 samples from Sohag). The results revealed that about $83 \%$ of the samples contained residues of one or more organochlorine pesticides. The study comprised six of organochlorine compounds which earlier were used mostly as insect- controlling pesticides. These are: p,p'-DDT with its metabolites p,p'-DDE and p,p'-DDD(the values for these three substances were reported here as the sum of the three, referred to as DDT complex), dielderin, endrin, heptachlor, heptachlor epoxide, and lindane

The present study revealed that $25 \%$ of the samples were contaminated by two types of organochlorine pesticide residues and $7.5 \%$ of the samples were contaminated by three types which increase the hazards on health. Windham 2002 reported that mixtures of low levels of organochlorine chemicals were found to cause significantly greater proliferation of tumour cells than individual exposures. Although the use of DDT and other organochlorines was banned in Egypt many years ago, the present study revealed its presence in $30 \%$ of the analyzed milk samples followed by lindane and heptachlor in $22.5 \%$, endrin in $17.5 \%$, and lastly dieldrin and heptachlor epoxide in $15 \%$ of the analyzed samples. This could be explained by the wide spread of organochlorine pesticide contaminants in most of the Egyptian governorates. This is in agreement with (ElGebaly, 2000) who detected organochlorine residues in milk samples collected from Cairo, Giza and El-Kaliobia Governorates and (Dogheim et al., 1988 and 1996), who detected organochlorine pesticide contaminants in milk samples collected from Beni-Suef and ElGharbia Governorates. As a result of the legal banning of organochlorine pesticides use in Egypt since 1990 (National Resources Defense Council, 2003), there was gradual decline of the values of DDT in food stuff as milk. Dogheim $\boldsymbol{e t}$ al., (1988), studied organochlorine pesticides in milk from Beni-Suef. They found that the mean concentration of DDT was 2.031 ppm. However, Dogheim et al., (1996) found that DDT level in dairy milk was much less than the previously estimated levels at 1988. DDT complex residues were detected in all analyzed samples of milk collected from some villages at Assuit Goveronarate during 1988, 1989 and 1992, with a mean values of $0.450,0.964$ and $0.168 \mathrm{ppm}$ respectively (Salem et al, 1994). El-Gebaly (2000) studied organochlorine compounds in Great Cairo, he found DDT-p,p in $25 \%$ of milk samples analyzed with a mean value of 0.173 ppm. However, DDT values in the present study $(0.1003 \pm 0.019 \mathrm{ppm})$ was lower than the previous values.

The data available from a large number of countries, showed that DDT has become widely disseminated in milk. Kalra et al., (1978) studied DDT contamination of milk collected from different localities in Punjab, India. They found that DDT ranged from 0.006 to 0.13 . Another study in India, Kaphalia et al., 1990 found DDTin $60 \%$ of milk samples with a mean concentration of $\mathbf{0 . 0 2 8}$ ). In Iraq Al-Omar et al., 
(1985) studied pesticides contamination in milk from 4 localities around Baghdad, they found that DDT-p,p ranged from 0.01 to 0.05 ppm. In Spain, Martinez et al., (1997) found that one percent of milk samples were contaminated with DDT-p,p with a mean level of 0.007 .

In the present study the mean concentration of dieldrin was $0.1273 \pm 0.02 \mathrm{ppm}$. These values were slightly lower than the mean value of dieldrin detected by El-Gebaly (2000), which was 0.175 ppm in milk samples collected from Great Cairo. Al-Omar et al. (1985) detected dieldrin in milk samples around Baghdad, Iraq, in levels ranging from 0.01 to $0.02 \mathrm{ppm}$. Fytianos et al., (1985) found that the mean value of dieldrin was $0.15 \mathrm{ppm}$. in milk collected from Germany. The present results were much higher than those reported in Spain by Martinez et al. (1997), who detected dieldrin in $72.2 \%$ of analyzed milk samples with a mean level of 0.028 ppm.

In the present study, lindane was detected in a mean value of $0.17 \pm 0.016 \mathrm{ppm}$. The detected values were less than that detected by El-Gebaly (2000), who detected lindane in $30 \%$ of milk samples from Great Cairo with a mean value of $0.53 \mathrm{ppm}$.). In Iraq Al-Omar et al. (1985 found that lindane ranged from 0.03 to $0.06 \mathrm{ppm}$. The mean values of lindane detected in the present study are much higher than those detected by Fytianos et al. (1985), who found that the mean value of lindane was $0.022 \mathrm{ppm}$ in German milk while in India, Kaphalia et al. (1990) found that the average level of lindane was 0.06 ppm.

Salem et al, (1994) reported an increase in the concentration of endrin residues in milk samples collected from Assuit villages in 1989 and 1992 versus low levels in 1988. This may be attributed to misuse or illegal use of endrin. Endrin in this work was found in $17.5 \%$ of the analyzed milk samples with a mean concentration of $0.058 \mathrm{ppm} \pm 0.013$. These results are lower than that obtained by El-Gebaly (2000) who detected endrin in $15 \%$ of samples collected from Great Cairo governorates with a mean concentration of $0.078 \mathrm{ppm}$. Al-Omar $\boldsymbol{e t}$ al. (1985) studied pesticides contamination of milk collected from areas around Baghdad, Iraq, and found that endrin levels ranged from 0.03 to 0.1 ppm.The results of the present studies are near those obtained by the previous studies.

Concerning heptachlor in milk samples in the present work, it was found that $22.5 \%$ were contaminated with heptachlor with a mean value of $0.0575 \mathrm{ppm} \pm \mathbf{0 . 0 1 3}$. On analyzing milk samples collected from Assuit Governorate during the years 1988, 1989 and 1992, Salem $e t$ al, (1994) reported that the residual amounts of heptachlors(heptachlor and its epoxide) were significantly decreased by the lapse of the time. The mean concentration of heptachlor in 1992 was 0.007 , which is much lower than the results obtained in the present work. Dogheim et al. (1988), studied pesticide residues in milk samples collected from Beni-Suef and found that the mean concentration of heptachlor was $0.063 \mathrm{ppm}$ and that only one sample exceeded the EC limit. These values are higher than those detected in this study. The previous results revealed that the use of heptachlors in Sohag and Qena Governorates is much higher than that in Assiut and other upper Egypt Governorates. The mean value of heptachlor in the present is nearly double that obtained from the analysis of milk samples in Great Cairo by El-Gebaly (2000). In Spain, Pozo et al. (1990) found that the mean value of heptachlor in milk was $0.002 \mathrm{ppm}$. Also the mean values of heptachlor detected in the present study is five times higher than those detected in Spain by Martinez et al. (1997). 
In the present study, heptachlor epoxide has been detected $15 \%$ of the analyzed milk samples with a mean concentration of $0.053 \pm 0.01 \mathrm{ppm}$. None of the milk samples collected from Great Cairo that were analyzed by El-Gebaly (2000) showed contamination with heptachlor epoxide. The Hawaiian State Department of Health detected high amounts of heptachlor epoxide in cow's milk in 1982. Levels of heptachlor epoxide in cow's milk were reported to be as high as 1.2 to 2.7ppm (Smith, 1982). Westlake et al (1993) indicated that toxic residues of heptachlor epoxide, will persist in soil for about 9 years, the possibility thus exists for contamination of crops of these fields, subsequently stored in fat of dairy cows and excreted in the milk for an extended period. DDT was the most frequent organochlorine pesticide detected in Qena followed by heptachlor whereas DDT and lindane were the most frequent organochlorine pesticides detected in Sohag followed by heptachlor and dieldrin.

Assuming that a person weighting $60 \mathrm{~kg}$. consumes two glasses of milk per day $(343 \mathrm{ml})$, the average daily intake of organochlorine pesticides was calculated and compared with the accepted daily intake data from the Food and Agriculture Organization/World Health Organization (FAO / WHO, 1993). It was found that none of the studied pesticides exceeded the recommended limits.

The results of this work indicated that in spite of the banning much of organochlorine pesticides still contaminating the environment resulting in contamination of food stuffs, particularly milk. There is a potential risk of the consumption of such contaminated milk on human's health particularly infants and children. Organochlorine's use is able to produce untoward effects of varying degrees, both on human and environment. Some of them are of a serious nature, causing irreversible damage at a rather low level (WHO, 2003).

\section{REFERENCES:}

Al-Omar, M.A.; Al-Bassomy, M.; Al-Ogally, N. and Shebel, D.A. (1985): Residue levels of organochlorine insecticides in dairy milk from Baghdad. Bull. Envir. Contam. Toxicol., 34: 509-512.

Clarke, E.G.C. (1986): Isolation and identification of drugs. Cited in Sidny $K$. :hand book of emergency toxicology, a guide for identification, diagnosis and treatment of poisoning. Charles. USA, Fifth Ed, 1988, 285-286.

Dogheim, S. M.; Almaz, M. M.; Kostandy, S.N. and Hegazy, M. E., (1988): Pesticide residues in milk and fish samples collected from Upper Egypt. J. Assoc. Off. Anal. Chem., 71, 872-874.

Dogheim, S. M.; El- Karka, M.; Gad Allah, S. A.; El-Sayed, S.; Salma, E.Y.; Ayoub, M. M. and Fahmy, S. M., (1996): Monitoring of pesticides residues in human milk, soil, water and food samples collected from Kafr El-Zayat Governorate. J. Assoc. Off. Anal. Chem. Int., 79, 1, 111-116.

El-Gebaly, F., (2000): Detection of organochlorine pesticides residue in animal milk collected from Great Cairo Governorate. In: Thesis of Forensic Medicine and Toxicology (Al-Azhar University), 117-137.

FAO/WHO, (1993): Codex Alimentarius: Pesticide residues in food. Vol. $2,2^{\text {nd }}$ Ed, Joint FAO/WHO Food slandered program Codex Alimentarius Commission, 25-35. Report paper 62.

Fiedler, H.; Hutzinger, O.; Welsch-Pausch, K. and Schmiedinger, A., (2000): Evaluation of the occurrence of PCDD/PCDF and POPs in waste and their potential to enter the food chain, University of Bayreuth, Ecological Chemistry and Geochemistry coordination by the Joint 
Research Center, Environmental Institute, 15-17.

Fytianos, K.; Vasilikiotis, J.; Weil, L.; Kavlengis, E. and Laskaridis, N. (1985): Preliminary study of organochlorine compounds in milk products, human milk and vegetables. Bull. Environ. Contam. Toxicol. Vol.34: 504-508.

Hayes, WJ (1991): Chlorinated hydrocarbon insecticides. In: Hayes WJ, Lawes ER: Pesticides Studied in Man. San Diego, Academic Press, 731-868.

Heeschen, W. and Harding, F. (1995): Milk quality and contaminants. Elsevier Applied Science, London, Vol.3, 133-150.

Joy, R.M., (1982): Chlorinated hydrocarbon insecticides. In: Pesticides and Neurological Diseases, edited by D. J. Ecobichon and R.M. Joy. CRC Press, Boca Raton, 91-150.

Kalra, R. L.; Chawla, R. P.; Dhaliwal, G. S. and Joya, B. S., (1978): DDT and HCH residues in food stuffs in Punjab. Proc. Symp. Nuclear Techniques in studies on metabolism. Effects and degradation of pesticides. Department of atomic energy, Bombay, Quoted from pesticides, their ecological impact in developing countries, Dhaliwal, G. S. ed. Commonwealth Publishers, New Delhi, India, 19-30.

Kaphalia, B. S.; Takroo, R.; Mehrotra, S.; Nigan, U. and Seth, T. D., (1990): Organochlorine pesticide residues in different Indian cereals, spices, vegetables, fruits, milk, butter, and edible oils. J. Assoc. Off. Anal. Chem., Vol. 73, 509-512.

Martinez, M. P.; Angulo, R.; Bozo, R. and Jodral, M. (1997): Organochlorine pesticides in pasteurized milk and associated health risks. Food and Chemical Toxicology. 35: 621-624.

National Resources Defense Council, (2003): Healthy milk, healthy baby, chemical pollution and mother's milk. File: // NRDC Healthy Milk, Healthy BabyDieldrin, Aldrin, and Endrin.html.

Pozo, R.; Herrera, A.; Polo, L. M.; Loper, R.; Jodral, M. and Iglesias, J., (1990): Hexachlorobenzene contamination of cow's whole milk in Southern Spain. Arch. Zoo., 26:45-63.

Robertson G., Lebwitz M., Needham L., O'Rourke M.K., Rogan S., Petty J. and Huckins J. (2002): Distribution of residential organochlorine pesticide residues along Arisona/Mexico border. Proceeding: Indoor air, 63-6-68.

Salem, D. A.; Shaaban, A. A.; Schuller, W.; Dogheim, M.; Salwa and Shehata, A. M., (1994): Organochlorine pesticide residues in buffalo milk at Assuit governorate. Proceeding of the second Egypt. Int. Cong. Of Legal Medicine, 207-215.

Smith, R. J., (1982): Hawaiian milk contamination creates alarm, Science, 217, 137-140.

Tilman S. (2003):Belgium, occupational and environmental medicine, 60: 348-51.

Watterson, A. (1991): Pesticides and your food (Green print). In: New Internationalist 323 May.

Westlake, W. E.; Corley, C.; Murphy, R. T.; Barthal, W. F.; Brant, H. and Schatzmann, R. L., (1993): Chemical residues in milk of cows grazed on chlordane-treated pasture. J. Agric. Food Chem., 11: 244-246.

windham B. (2002): The health effects of pesticides. (Ed.) 6-1, pesticid. htm 24/07/1425.

World Health Organization (WHO) (2003): Persistent organic pollutants compiled by the program for the promotion of chemical safety, The Division of Control of Tropical Diseases, and the Food Safety Unit. http://www. Chem. UNEP.Ch/ POPs /indxhtms/manexp12.html 


\section{الكشف عن متبقيات المبيدات الكلورينية العضوية

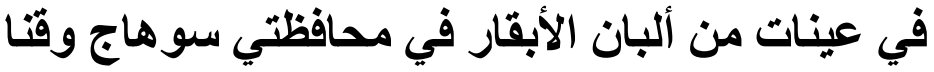

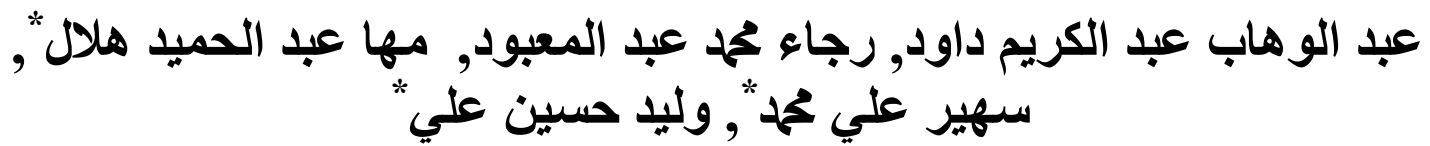

قسما الطب الشرعي والسموم بكليتي الطب - جامعتي أسيوط وجنوب الوادي "

على الرغم من مزايا استخدام المبيدات الحشرية في زيادة الإنتاج الزراعي والنهوض بالصحة العامـة من خلال السيطرة

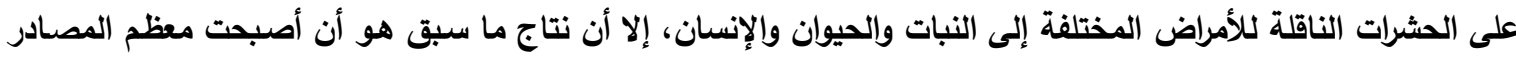
الغذائية تحتوى على متبقيات من المبيدات الحشرية، إذ أن معظم المبيدات العضوية الكلورينية بطيئة في تحلاهها، كما أنها

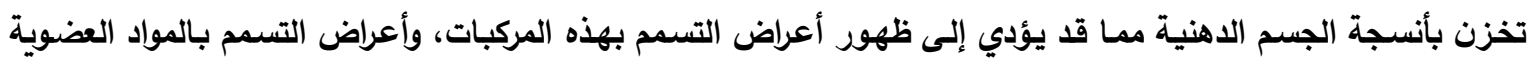

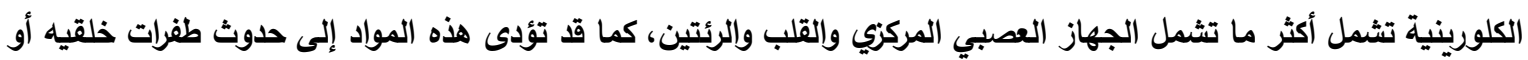
حدوث سرطان. ومن أهم المصادر الغذائية التي قد تحتوى على متبقيات عضويه كلئ كلورينية هي منتجات الألبان التي تعتبر

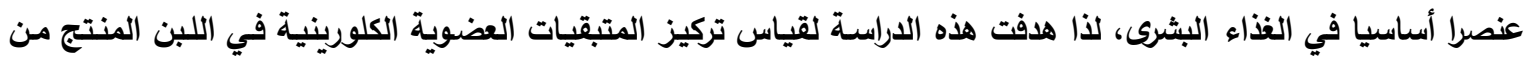

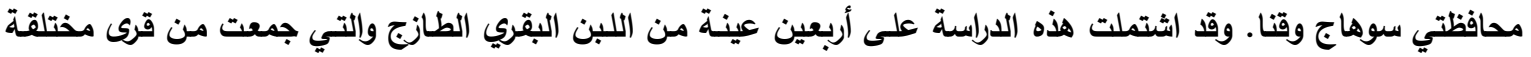

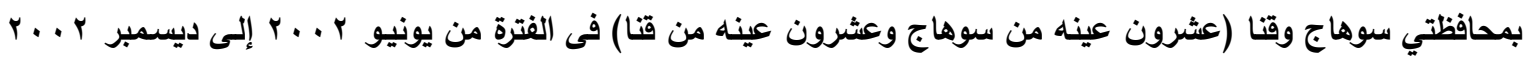

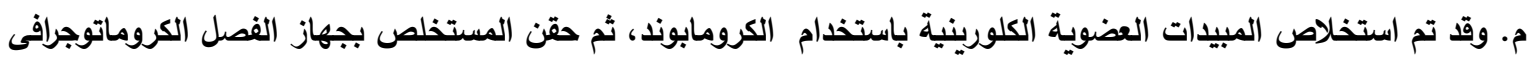
السائل ذو الكفاءة العالية للتعرف على وتعيين قيم متبقيات المبيدات الكلورينية العضوية.

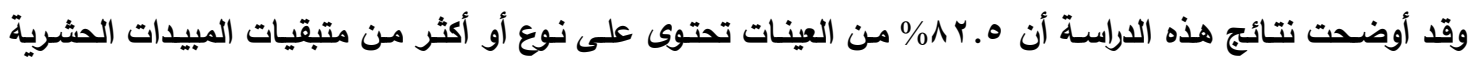

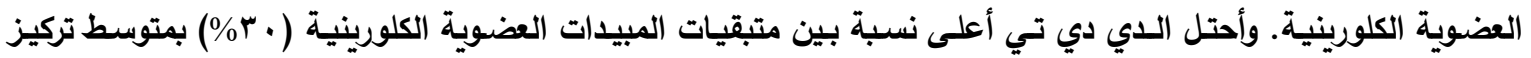

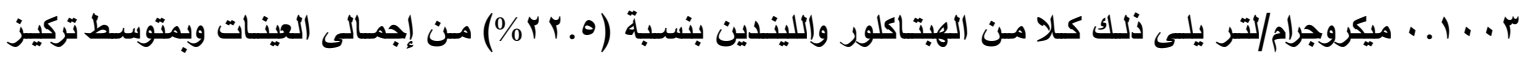

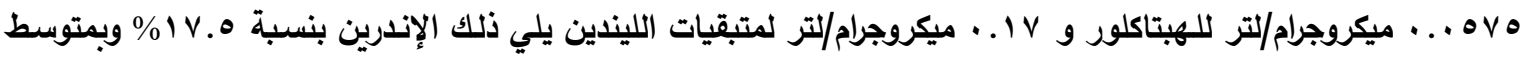

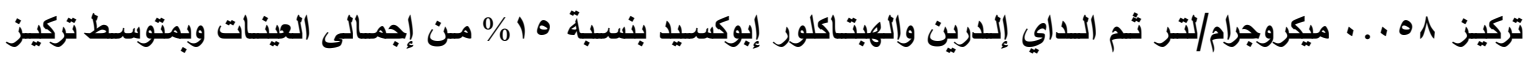

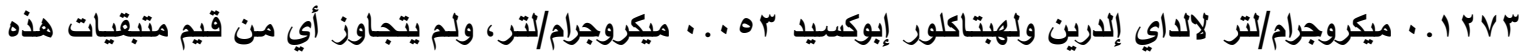
المبيدات في عينات الألبان المعدلات المسموح بها دولياً.

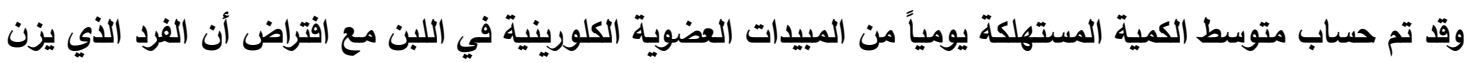

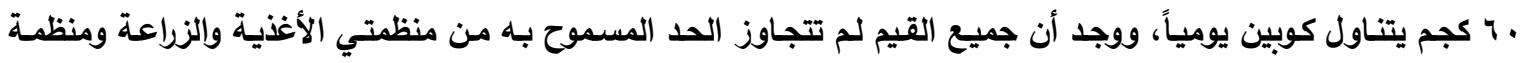

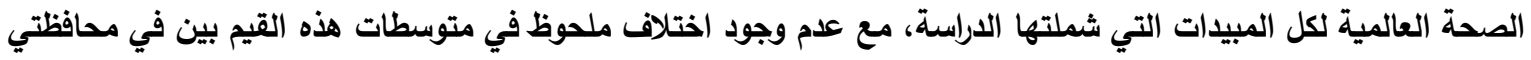

ولقد أوصت الدراسة بضرورة استمرار الرقابة الدقيقة على استخدام المبيدات العضوية الكلورينية، وكذلك أن تتم دراسات

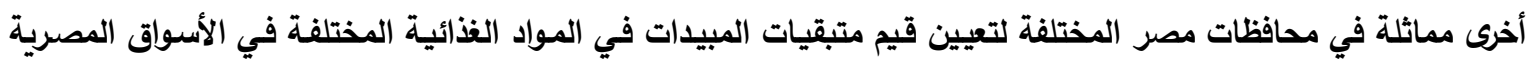
لتقدير المخاطر الصحية التي يتعرض لها الإنسان المصري عند تناول هذه الأغذية الملوثة. 